\title{
Cigarette smoke is associated with altered expression of antioxidant enzymes in granulosa cells from women undergoing in vitro fertilization
}

\author{
Maria Cristina Budani ${ }^{2}$, Erminia Carletti ${ }^{3}$ and Gian Mario Tiboni ${ }^{1}$ \\ Department of Medicine and Aging Sciences, University 'G. d'Annunzio' Chieti-Pescara, Italy; and Department of Medical, \\ Oral and Biotechnological Sciences, University 'G. d'Annunzio' Chieti-Pescara, Italy
}

Date submitted: 13.12.2016. Date revised: 24.02.2017. Date accepted: 01.04.2017

\section{Summary}

This study was undertaken to evaluate whether cigarette smoke is associated with changes in the expression of antioxidant enzymes in granulosa cells of women undergoing IVF treatments. For this aim, the expression of three antioxidant enzymes (SOD1, SOD2 and catalase) in non-smokers $(n=20)$ and smokers $(n=20)$ was analyzed. There was a statistically significant overexpression of SOD2 and catalase mRNA levels in smokers in comparison with non-smokers. Cigarette smoking was associated with a lower fertilization rate, implantation rate and pregnancy rate in comparison with non-smokers. There was no effect on retrieved oocytes number, metaphase II oocytes number, quality of embryos transferred and live birth rate. These findings suggest that cigarette smoke initiates oxidative stress in granulosa cells.

Keywords: Antioxidant enzymes, Cigarette smoke, Granulosa cells, In vitro fertilization, Oxidative stress

\section{Introduction}

Smoking remains a worldwide health issue. Cigarette smoke contains about 4000 chemical substances, most of which have known toxic effects. These substances include polycyclic aromatic hydrocarbons (PAHs) such as benzoapyrene, nitrosamises, heavy metals (cadmium), alkaloids (nicotine end its major metabolite, cotinine) and aromatic amines. Possibly reflecting the multiple toxicological effects and targets of the chemicals contained in cigarettes, smoking has been causally related with a wide spectrum of deleterious effects on womens' reproductive processes (Dechanet et al., 2011). These include early menopause, premature follicle loss, abnormal follicle growth and

\footnotetext{
${ }^{1}$ All correspondence to Gian Mario Tiboni. Department of Medicine and Aging Sciences, University 'G. d'Annunzio' Chieti-Pescara, Via dei Vestini 66013 Chieti, Italy. Tel: +39 0859172390. E-mail: tiboni@unich.it

${ }^{2}$ Department of Medicine and Aging Sciences, University ‘ $G$. d'Annunzio' Chieti-Pescara, Italy.

${ }^{3}$ Department of Medical, Oral and Biotechnological Sciences, University 'G. d'Annunzio' Chieti-Pescara, Italy.
}

impairment of morphology and oocytes maturation (Neal et al., 2007; Sadeu \& Foster 2011; Jennings et al., 2011; Paixao et al., 2012). Different studies have evaluated the molecular mechanisms behind the ovotoxicity elicited by cigarette smoke (Nampoothiri et al., 2007; Tuttle et al., 2009; Sobinoff et al., 2012, 2013; Gannon et al., 2012, 2013, Ganesan et al., 2013, Mai et al., 2014), with redox balance alteration regarded as a main molecular determinant implicated (Nampoothiri et al., 2007; Lim \& Luderer., 2011; Sobinoff et al., 2012, 2013; Mai et al., 2014 Siddique et al., 2014; Opuwari \& Henkel, 2016).

The term redox balance indicates the physiological stability between free radicals and antioxidant defense. Cells are protected by defense systems in order to prevent oxidative damage and remove free radicals. An alteration of this balance towards an increase in pro-oxidants other than anti-oxidants establishes a condition called oxidative stress (Valko et al., 2007). Among the free radicals, the main reactive oxygen species include superoxide anion $\left(\mathrm{O}_{2}^{-}\right)$and hydrogen peroxide $\left(\mathrm{H}_{2} \mathrm{O}_{2}\right)$ that are physiologically stabilized by cytosolic copper-zinc superoxide dismutase (SOD1) and mitochondrial manganese-SOD (SOD2) 
and catalase respectively. In particular, SOD1 and SOD2 reduce superoxide anion to hydrogen peroxide and molecular oxygen (Valko et al., 2007):

$$
2 \mathrm{O}_{2}^{-}+2 \mathrm{H}^{+}+2 \mathrm{e}^{-} \rightarrow \mathrm{H}_{2} \mathrm{O}_{2}+\mathrm{O}_{2} .
$$

Catalase reduces hydrogen peroxide to water (Valko et al., 2007):

$$
\mathrm{H}_{2} \mathrm{O}_{2}+\mathrm{H}_{2} \mathrm{O}_{2} \rightarrow 2 \mathrm{H}_{2} \mathrm{O}+\mathrm{O}_{2} .
$$

There is evidence that cigarette smoke exposure is associated with an increase in ROS formation in oocytes (Sobinoff et al., 2012, 2013), in follicles cultured in vitro (Siddique et al., 2014), and in mice ovaries exposed to this stress (Mai et al., 2014). Little information is known about the effects of cigarette smoke exposure on granulosa cell redox status. Granulosa cells (GCs) are steroidogenic cells that surround the oocyte and have an important role in follicular development, oocyte maturation and atresia (Karuputhula et al., 2013). Antioxidant enzymes play an important role in protection from oxidative stress damages. At very low concentration, ROS are second messengers that are important to modulate the expression of genes enrolled in physiological process of gametes and embryos, such as oocyte maturation, ovarian steroidogenesis, luteolisis and corpus luteal functions (Agarwal et al., 2005). An increase in reactive oxygen species concentration induces pathological processes that involve the female reproductive tract.

Antioxidant enzymes have been localized in the granulosa and thecal cells of the growing follicle (Agarwal et al., 2005). In particular, in granulosa cells, antioxidant enzymes play an important role in scavenging reactive oxygen species generated during the synthesis of steroid hormones, and catalase activity is stimulated by both FSH and an increase in $\mathrm{E}_{2}$ levels (Tatone et al., 2006).

The aim of this study was to evaluate, for the first time, the consequences of the habit of smoking on the levels of antioxidant enzymes (SOD1, SOD2 and CAT) in granulosa cells of women smokers undergoing IVF treatments.

\section{Materials and methods}

\section{Patient selection}

In total, 40 women, attending an IVF programme in the unit for assisted reproductive technology of the Ortona General Hospital, Italy, were studied. The study group consisted of 20 smokers [ $13 \pm 6$ cigarettes/day; mean \pm standard deviation (SD)] and 20 non-smoking patients who were undergoing IVF techniques. Patients taking micronutrient supplements were excluded from the study. Patients' smoking habits were assessed by a questionnaire. The authors assert that all procedures contributing to this work comply with the ethical standards of the relevant national and institutional committees on human experimentation and with the Helsinky Declaration of 1975, as revised in 2008.

Ovarian stimulation was induced in all patients using a combination of GnRH agonist/antagonist and recombinant FSH (Puregon; Merck Shape and Dome, Italy; Gonal F, Merck Serono, Italy) at the starting daily doses ranging from $150 \mathrm{IU}$ to $225 \mathrm{IU}$. The stimulation was controlled using serum estradiol measurement and serial ultrasound amounts of follicle numbers and diameters. Oocyte retrieval was performed by transvaginal aspiration $36 \mathrm{~h}$ after recombinant hCG (Ovitrelle, Merck Serono, Italy) administration. The luteal phase was supported with intramuscular injections of $100 \mathrm{mg}$ progesterone (Prontogest, IBSA, Italy). A pregnancy test was performed by quantifying serum beta-hCG 14 days after embryo transfer. Clinical pregnancy was defined as the presence of a gestational sac with fetal heart activity visible on an ultrasound scan at 7 weeks' gestation.

\section{GCs isolation and in vitro fertilization}

For each patient enrolled in this study, follicular aspirates, free of blood contamination, after removal of the oocyte, were collected in a tube that was left standing for 5 min to allow mural GCs to sediment. The cell pellet was gently re-suspended in $5 \mathrm{ml}$ of Ham's F-10 medium (Sigma Aldrich). After centrifugation on a density gradient (Ficoll-Hypaque; Sigma Aldrich) at $3000 \mathrm{rpm}$ for $10 \mathrm{~min}$, GCs were purified collecting the top layer of the suspension and taking care to avoid the layers containing lymphocytes and red blood cells. GCs were washed with $5 \mathrm{ml}$ of Ham's F-10 medium and to prevent cell aggregation, were treated with hyaluronidase solution $(0.1 \% \mathrm{vol} / \mathrm{wt}$ in Ham's F-10) for $15 \mathrm{~min}$. The entire procedure was completed within $1 \mathrm{~h}$ after follicle aspiration to prevent cell death.

After $2 \mathrm{~h}$ from ovum pick-up, eggs were denuded and their stage of maturation was recorded. Oocytes in metaphase II stage were fertilized by intracytoplasmic sperm injection (ICSI). Italian legislation requires that embryo production must not exceed what is strictly necessary based on individual patient characteristics. Embryos were classified into types A, B, and C according to the following morphological characteristics (Tiboni et al., 2012): type A or excellent embryos composed with regular blastomeres with equal or nonequal size without fragmentation; type B or good embryos with blastomeres of equal or non-equal size with $<$ of $20 \%$ of the embryo volume with enucleate fragments; and type $\mathrm{C}$ or fair embryos with anucleate fragments in $20-50 \%$ of the volume of the embryo. 


\section{SOD1, SOD2 and catalase mRNA quantification by qRT-PCR}

\section{Total RNA extraction}

Total RNA was isolated and subjected to DNase I treatment, using the RNAqueous-4 PCR Kit (ThermoFisher Scientific) according to the manufacturer's instructions. RNA concentrations were quantified by determination of optical density at $260 \mathrm{~nm}$ and $280 \mathrm{~nm}$ on a UV spectrophotometer. All RNA used in this study had a 260:280 ratio between 1.9 and 2.1. The integrity of the RNA sample was confirmed by agarose gel electrophoresis, which showed the presence of intact $18 \mathrm{~S}$ and $28 \mathrm{~S}$ ribosomal RNA bands.

\section{Reverse transcription}

Synthesis of cDNA was performed using the HighCapacity Reverse Transcription Kit (ThermoFisher Scientific) with the reaction conditions recommended by the manufacturer. Briefly, a mixture containing $1 \mu \mathrm{g}$ of RNA, $2 \mu 110 \times$ RT Buffer, $0.8 \mu 1$ of $25 \times$ dNTP $100 \mathrm{mM}$ mixture, $2 \mu 1$ 10× Random Primers, $1 \mu$ l MultiScribe Reverse Transcriptase (50 U/ $\mu 1), 1 \mu 1$ RNase Inhibitor $(20 \mathrm{U} / \mu \mathrm{l})$ and RNAse-free water to reach a final volume of $20 \mu \mathrm{l}$. The reaction was incubated at $25^{\circ} \mathrm{C}$ for $10 \mathrm{~min}, 37^{\circ} \mathrm{C}$ for $120 \mathrm{~min}, 85^{\circ} \mathrm{C}$ for $5 \mathrm{~min}$ and then at $4^{\circ} \mathrm{C}$. cDNAs were stored at $-20^{\circ} \mathrm{C}$ until use.

\section{Quantitative real-time PCR}

Quantitative real-time PCR assays (ABI PRISM 7700 Sequence Detection System User Bulletin\#2 P7N 4303859, Applied Biosystems, USA) for the Relative Quantitation of human superoxide dismutase 1 (SOD1), superoxide dismutase 2 (SOD2) and catalase (CAT) gene expression versus the endogenous control gene glyceraldehyde-3-phosphate dehydrogenase $\left(\right.$ GAPDH), were performed using TaqMan ${ }^{\mathrm{TM}}$ technology (PE Applied Biosystems, USA ThermoFisher Scientific) on the ABI Prism 7900 HT Sequence Detection System Instrument (PE Applied Biosystems, USA), connected to a Sequence Detector Software (SDS version 2.0, PE Applied Biosystems, USA) for collection and analysis of data. We previously validated GAPDH as housekeeping gene in this cell type.

According to manufacturer recommendation the reaction mixture $(25 \mu \mathrm{l})$ for each gene and endogenous control gene (GAPDH) was prepared as follows: 0.5 $\mu \mathrm{l}$ of cDNA obtained from $1 \mu \mathrm{g}$ of transcripted RNA, $12.5 \mu$ TaqMan Universal PCR Master Mix $2 \times, 1.25 \mu \mathrm{l}$ TaqMan Gene Expression Assay 20x, containing a FAM dye-labeled TaqMan MGB probe and 2 unlabeled PCR primers, and RNAse free-water to reach a final reaction volume of $25 \mu \mathrm{l}$. Reactions were performed in a MicroAmp Optical 96-well reaction plate (PE Applied Biosystems, USA). Amplification conditions were $95^{\circ} \mathrm{C} 10 \mathrm{~min}$ (hot start), followed by 40 cycles of $95^{\circ} \mathrm{C} 15 \mathrm{~s}, 60^{\circ} \mathrm{C} 1 \mathrm{~min}$. All reactions were performed in triplicate and repeated twice. The relative quantification of SOD1, SOD2 and CAT gene expression was evaluated with data from SDS Software. Within each experiment, the fold change between treatment and control was determined by transforming logarithmic data to linear data using the arithmetical formula: $\mathrm{RQ}=2^{-\Delta \Delta \mathrm{CT}}$, according to the comparative $C_{t}$ method, where $\Delta \Delta C T=\left(\right.$ Avg. $C_{T}$ gene $x$ in smoker - Avg. $C_{T}$ GAPDH in smoker) (Avg. $C_{T}$ gene $x$ in non-smoker - Avg. $C_{T}$ GADPH in non-smoker), where Avg. $C_{T}$ is the average of $C_{T}$ numbers of three replicates in the smoking or not smoking group. The values represent the fold change of the gene in the smoker group relative to nonsmoker one. For the $\Delta \Delta C_{T}$ calculation to be valid, relative efficiency plots were performed. The efficiency of the target amplification and the efficiency of the reference amplification must be approximately equal (ABI PRISM 7700 Sequence Detection System User Bulletin \#2 P7N 4303859, Applied Biosystems, USA; not shown). A sensitive method for assessing if two amplicons have the same efficiency is to look at how $\Delta C_{T}$ varies with template dilution. We found that GAPDH responded to these parameters as assumed by ABI PRISM 7700 Sequence Detection System User (Bulletin \#2 P7N 4303859, Applied Biosystems, USA).

\section{Outcome measures and statistical analysis}

Statistical analysis was performed using the chisquared test for proportions, and Student's $t$-test for continuous variables. A $P$-value $<0.05$ was considered as significant.

\section{Results}

\section{SOD1, SOD2 and CAT gene expression in GCs of smokers and non-smokers}

We carried out qRT-PCR analysis on GCs isolated from a pool of follicles of each patient in order to evaluate mRNA levels of SOD1, SOD2 and catalase in smokers and non-smokers. Figure 1 shows the relative mRNA levels between the two groups. These data revealed an overexpression of SOD1, SOD2 and catalase mRNA levels in smokers. In particular, the relative level of SOD2 mRNA in smokers was $1.7 \pm 1.2$, whereas for non-smokers it was $1.0 \pm 0.3$ (Fig. 1B). The difference was statistically significant $(P=0.03)$. In the same way, catalase expression was upregulated in GCs retrieved from smokers. The relative level of catalase mRNA in this group was $1.6 \pm 0.7$ whereas for non-smokers it 
A.

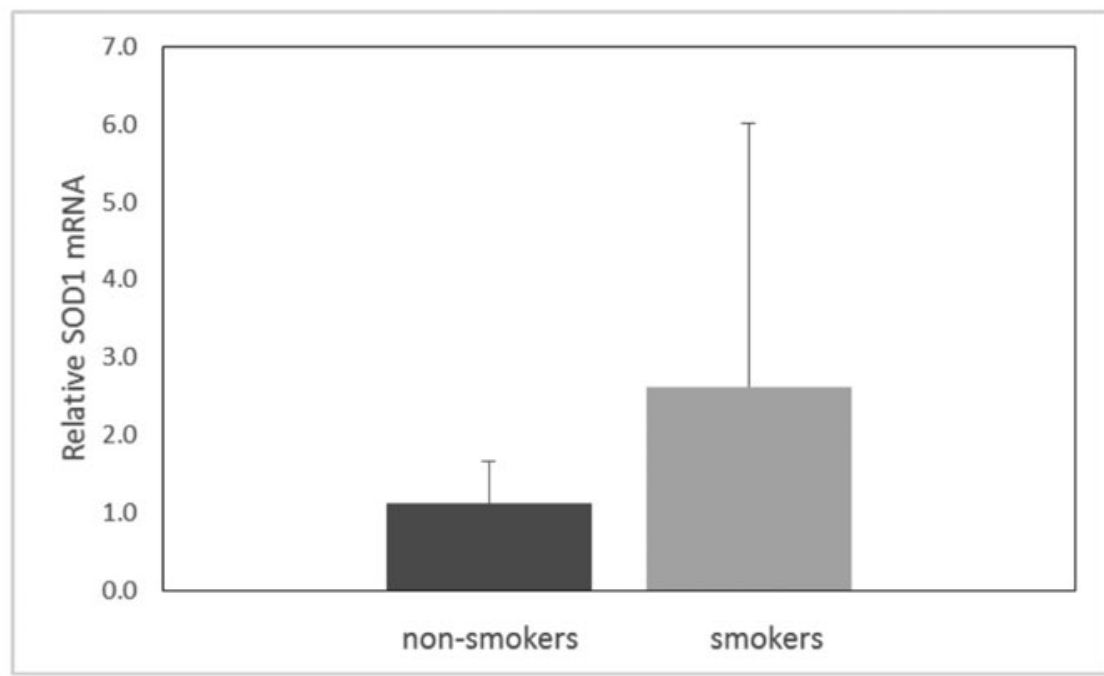

B.

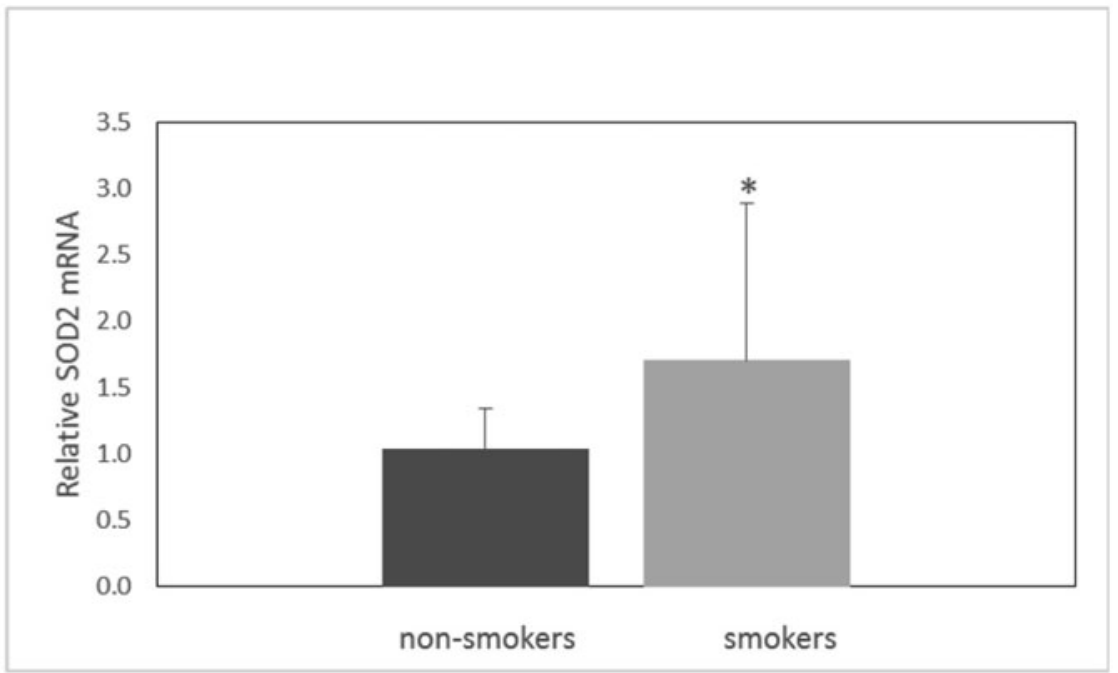

c.

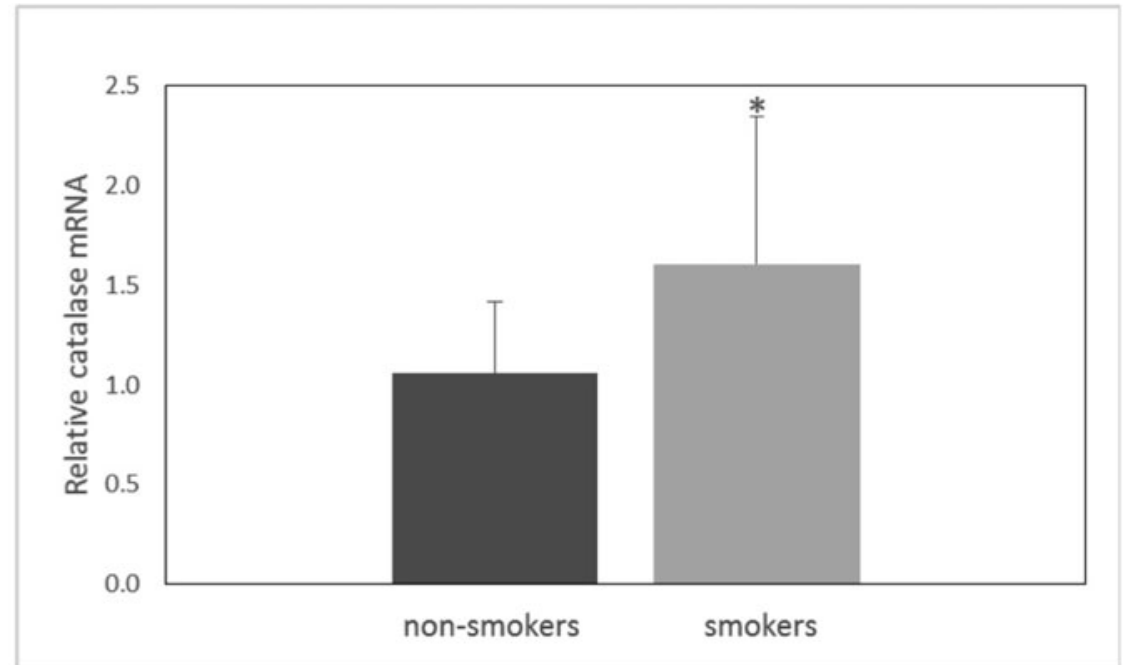

Figure 1 SOD1 (A), SOD2 (B) and catalase (C) mRNA expression levels in granulosa cells from non-smoker and smoker patients. Values are means \pm SD from comparative real time results obtained from non-smoker $(n=20)$ and smoker $(n=20)$ patients enrolled in the study. Student's $t$-test was used for statistical analysis for smoker versus non-smoker patients: ${ }^{P} P<0.05$. 
Table 1 Main demographic and baseline characteristics of non-smoker and smoker patients

\begin{tabular}{lccc}
\hline & Non-smokers $(n=20)$ & Smokers* $(n=20)$ & $P$-value \\
\hline Mean age in years & $32.8 \pm 4.1$ & $33.7 \pm 3.8$ & NS \\
Mean body mass index $(\mathrm{kg} / \mathrm{m} 2)$ & $21.5 \pm 3.5$ & $22.5 \pm 3.6$ & NS \\
Basal FSH & $7.4 \pm 2.7$ & $7.2 \pm 2.3$ & NS \\
Etiology of infertility $(\%)$ & & $11 / 20(55.0 \%)$ & NS \\
Male & $9 / 20(45.0 \%)$ & & \\
Female: & & $3 / 20(15.0 \%)$ & NS \\
Fallopian & $2 / 20(10.0 \%)$ & $2 / 20(10.0 \%)$ & NS \\
More than one diagnosis & $4 / 20(20.0 \%)$ & $3 / 20(15.0 \%)$ & NS \\
Unexplained & $3 / 20(15.0 \%)$ & $1 / 20(5.0 \%)$ & NS \\
not specificated & $2 / 20(10.0 \%)$ & $1.5 \pm 0.7$ & NS \\
No. of IVF attempts & $1.6 \pm 1.1$ & & \\
${ }^{*} 13 \pm 6$ cigarettes/day. & & & \\
Values are expressed as means \pm SD or $n(\%)$. &
\end{tabular}

was $1.1 \pm 0.4$ (Fig. 1C). This difference was statistically significant $(P=0.01)$.

\section{IVF outcome analysis}

Table 1 displays demographic and baseline characteristics of the two study groups. There were no statistically significant differences between the mean ages, causes of infertility, basal FSH and body mass index (BMI). Table 2 shows IVF outcomes of the two study groups. Comparable results were observed in terms of number of retrieved oocytes, number of metaphase II oocytes, quality of transferred embryos, live birth rate, twin pregnancy and pregnancy loss. Conversely, fertilization rate, implantation rate and clinical pregnancy rate were significantly different between smokers and non-smokers patients. In particular, smokers had a lower fertilization rate compared with non-smokers $(73 \%$ in non-smokers versus $56 \%$ in smokers). Regarding the implantation rate, it was $22.8 \%$ in non-smokers and $5.3 \%$ in smokers $(P=0.008)$. Our study revealed also a $55 \%$ rate of clinical pregnancies in non-smokers, and $10 \%$ rate of clinical pregnancies in smokers $(P=0.002)$.

\section{Discussion}

This study analyzed the relationship between cigarette smoking and antioxidants levels in human granulosa cells and a correlation between the habit of smoking in women and clinical outcomes of assisted reproductive techniques.

Experimental studies on animal models focusing on the effects of cigarette smoke on ovaries showed interesting results. Nampoothiri et al. (2007) and Sobinoff et al. (2012) demonstrated that cigarette smoking is correlated with an alteration in the redox balance in oocytes and granulosa cells exposed in vitro to compounds in cigarettes. In particular, Nampoothiri et al. (2007) established a significant decrease in SOD activity and GSH content, and a significant increase in catalase activity after lead and cadmium administration to rat granulosa cells. This altered balance between free radicals and antioxidants in granulosa cells was associated with an increased lipid peroxidation in GCs membrane structures. Sobinoff et al. (2012) tested the effects of $\mathrm{BaP}$ on mouse ovarian transcriptome, demonstrating that $\mathrm{BaP}$ exposure is associated with increased levels of mitochondrial ROS in oolemma membrane resulting in a considerable plasma membrane lipid peroxidation. Siddique et al., (2014) and Mai et al., (2014) found an impact of cigarette smoke on antioxidant enzymes in follicles cultured in vitro and in mouse ovaries exposed to this stress, respectively.

Previous studies conducted on women undergoing IVF treatments, demonstrated that age influences antioxidant enzyme expression in follicular fluid (Carbone et al., 2003) and in granulosa cells (Tatone et al., 2006). Carbone et al. (2003) found that follicular fluid from older women exhibited a reduced level of glutathione transferase and catalase activities and a higher level of SOD activity. Tatone et al. (2006) found a reduced expression of SOD1, SOD2 and catalase in granulosa cells of women $\geq 38$ years. Recent findings (Ávila et al., 2016) revealed that women with endometriosis and PCOS have lower antioxidant production capacity in their granulosa cells that may contribute to abnormal follicular development and infertility. A reactive oxygen species accumulation in the granulosa cells correlates with diminished expression of follicle-stimulating hormone receptor (FSHR) and a dysregulation of the FSHR signaling pathway and may be implicated in altered steroidogenic function and poor response to FSH in women (Ávila et al., 2016). 
Table 2 IVF cycle outcomes in non-smoker and smoker patients

\begin{tabular}{lccc}
\hline & Non-smokers $(n=20)$ & Smokers $(n=20)$ & $P$-value \\
\hline Retrivied oocytes $(n)$ & $9.3 \pm 6.1$ & $8.8 \pm 4.5$ & $\mathrm{NS}$ \\
Metaphase II oocytes $(n)$ & $8.4 \pm 6.1$ & $7.5 \pm 4.4$ & $\mathrm{NS}$ \\
Fertilization rate & $57 / 78(73.0 \%)$ & $56 / 99(56.0 \%)$ & 0.02 \\
Grade A embryos-8 cells & $42 / 57(73.7 \%)$ & $37 / 56(66.0 \%)$ & $\mathrm{NS}$ \\
Grade A embryos-6 cells & $8 / 57(14.0 \%)$ & $13 / 56(23.0 \%)$ & $\mathrm{NS}$ \\
Grade B embryos-8 cells & $1 / 57(1.7 \%)$ & $1 / 56(1.8 \%)$ & $\mathrm{NS}$ \\
Grade B embryos-6 cells & $3 / 57(5.3 \%)$ & $2 / 56(3.6 \%)$ & $\mathrm{NS}$ \\
Grade C embryos and $<6$ cells & $3 / 57(5.3 \%)$ & $3 / 56(5.3 \%)$ & $\mathrm{NS}$ \\
Implantation rate & $13 / 57(22.8 \%)$ & $3 / 56(5.3 \%)$ & 0.008 \\
Clinical pregnancy rate & $11 / 20(55.0 \%)$ & $2 / 20(10.0 \%)$ & 0.002 \\
Twin pregnancy & $2 / 11(18.0 \%)$ & $1 / 2(50.0 \%)$ & $\mathrm{NS}$ \\
Triplets & - & - & - \\
Pregnancy loss & $1 / 11(9.0 \%)$ & $0 / 3(0.0 \%)$ & $\mathrm{NS}$ \\
Live birth rate & $12 / 13(92.0 \%)$ & $3 / 3(100.0 \%)$ & $\mathrm{NS}$ \\
\hline
\end{tabular}

Values are expressed as means \pm standard deviation (SD) or $n(\%)$.

To the best of our knowledge, this is the first study that evaluated the association between the habit of smoking and the antioxidant enzymes gene expression (SOD1, SOD2 and CAT) in granulosa cells of smoker women undergoing IVF treatments. We used mural granulosa cells for our experiments, which are somatic cells that constitute the oocyte microenvironment together with cumulus cells (Aydos et al., 2016). Mural granulosa cells have an important role for correct oocyte development; one of the main functions is arresting the oocyte in the meiotic phase until ovulation by secreting oocyte maturation inhibitor (Kawamura et al., 2011). When the menstrual cycle begins, these cells receive external hormone signals to resume oocyte maturation. This activation signal is then transmitted to the cumulus cells, which are in direct contact with the oocyte with gap junction interaction (Aydos et al., 2016).

We found a statistically significant increase in SOD2 and catalase mRNA levels in smokers and an increase, not statistically significant, in SOD1. It is well known for granulosa cells that the antioxidant enzymes evaluated in our study play an important role in scavenging superoxide anions and hydrogen peroxide generated during steroidogenesis (Tatone et al., 2006).

The overexpression of these genes found in this study is probably due to an accumulation of reactive oxygen species cigarette smoke-induced. These increased levels of antioxidant enzymes may represent a necessity of granulosa cells to act against cigarette smoke-induced reactive oxygen species in order to neutralize them and to prevent their diffusion into the oocyte (Carbone et al., 2003). It is known that oxidative stress plays a role in the etiopathogenesis of endometriosis, tubal factor infertility, and unexplained infertility (Ngo et al., 2009; Kumar et al., 2010; Menezo et al., 2016). The fact that patients suffering from these infertility factors were included in the study may have introduced confounding effects in the analysis of the results.

\section{Clinical effects}

In our report we found a strong influence of cigarette smoke on fertilization, implantation and clinical pregnancy rates. As previously shown, we found a fertilization rate of $73 \%$ in non-smokers and $56 \%$ in smokers. These results are in accordance with our previous study (Tiboni et al., 2004) demonstrating a higher percentage fertilization rate in non-smokers $(71.5 \%)$ than smokers $(55.9 \%)$ in a retrospective analysis of 70 female patients undergoing IVF treatments (17 smokers and 43 non-smokers).

Gruber et al., (2008) found an 85.7\% fertilization rate in non-smokers versus $78.2 \%$ in smokers in a retrospective study that included 130 patients undergoing ICSI procedure (72 smokers and 58 nonsmokers).

\section{Implantation rate}

Our findings are in line with Neal et al. (2005) and Benedict et al. (2011) who showed a significant decrease in the percentage of implants in smokers compared with non-smokers. In particular, Neal et al. (2005) found a rate of $12 \%$ in smokers compared with a $25 \%$ implant rate in non-smokers in a retrospective study of 225 female patients undergoing IVF procedures. Benedict et al. (2011) in their retrospective analysis of a prospective cohort study, showed a significant increase in the risk of implantation failure among women exposed to sidestream smoke. 


\section{Clinical pregnancy rates}

Different authors found, in accordance with our findings, a decrease in clinical pregnancies in smokers (see Neal et al., 2005; Waylen et al., 2009; Ben-Haroush et al., 2011; Freour et al., 2012). In particular, Neal et al. (2005) found a $40 \%$ rate of pregnancies in non-smokers and an $11.1 \%$ rate in smokers. Freour et al. (2012) showed a clinical pregnancy rate per transfer of $21.1 \%$ in smokers (35.3\% in non-smokers) in a retrospective study involving 277 women while Ben-Haroush et al. (2011) found an overall rate of $35.7 \%$ of clinical pregnancies in smokers (55.4\% in non-smokers) in a cohort study including 237 patients (42 smokers and 195 non-smokers). Waylen et al. (2009) in their metaanalysis with a computerized search demonstrated that patients who smoked had significantly lower odds of clinical pregnancy per cycle (OR $0.56,95 \%$ CI $0.43-$ $0.73)$ than non-smokers.

Our findings are in contrast with some other studies (Wright et al., 2006; Fuentes et al., 2010; Cinar et al., 2014). In a retrospective analysis of 389 patients, Wright et al. (2006) described that the cigarette-smoking habit does not affect IVF procedure outcomes. Fuentes et al. (2010) failed to note, in a cohort prospective study including 166 patients, a significant association between women who smoked and reduced pregnancy rate. They also found a lower implantation rate, which was non-statistically significant, among women exposed to cigarette smoke compared with those who were not. Cinar et al. (2014) did not determine a significant correlation between the adverse effects of cigarette smoking and IVF outcomes.

\section{Conflict of interest}

There are no conflicts of interest.

\section{Acknowledgements}

This study was supported by internal funds.

\section{References}

Agarwal, A., Gupta, S. \& Sharma, R. (2005). Role of oxidative stress in female reproduction. Reprod. Biol. Endocrinol. 14, 3-28.

Ávila, J., González-Fernández, R., Rotoli, D., Hernández, J. \& Palumbo, A. (2016). Oxidative stress in granulosa-lutein cells from in vitro fertilization patients. Reprod. Sci. 23, $1656-61$.

Aydos, A., Gurel, A., Oztemur Islakoglu, Y., Noyan, S., Gokce, B., Ecemis, T., Kaya, C., Aksu, A.T. \& Gur Dedeoglu, B. (2016). Identification of polycystic ovary syndrome (PCOS) specific genes in cumulus and mural granulosa cells. PLoS One 11, e0168875
Ben-Haroush, A., Ashekenazi, J., Sapir, O., Pinkas, H., Fisch, B. \& Farhi, J. (2011). High quality embyos maintain high pregnancy rates in passive smokers but not in active smokers. Reprod. Biomed. Online 22, 44-9.

Benedict, M.D., Missmer, S.A., Vahratian, A., Berry, K.F., Vitonis, A.F., Cramer, D.W. \& Meeker, J.D. (2011). Secondhand tobacco smoke exposure is associated with increased risk of failed implantation and reduced IVF success. Hum. Reprod. 26, 2525-31.

Carbone, M.C., Tatone, C., Delle Monache, S., Marci, R., Caserta, D., Colonna, R. \& Amicarelli, F. (2003)., Antioxidant enzymatic defences in human follicular fluid: characterization and age-dependent changes. Mol. Hum. Reprod. 9, 639-43.

Cinar, O., Dilbaz, Z., Terzioglu, F., Karahalil, B., Yucel, C., Turk, R., Taskin, L. \& Kose, S.K. (2014). Does cigarette smoking really have detrimental effects on outcomes of IVF? Eur. J. Obstet. Gynecol. Reprod. Biol. 174, 106-10.

Dechanet, C., Anahory, T., Mathieu Daude, J.C., Quantin, X., Reyftmann, L., Hamamah, S., Hedon, B. \& Dechaud, H. (2011). Effects of cigarette smoking on reproduction. Hum. Reprod. Update 17, 76-95.

Freour, T., Masson, D., Dessolle, L., Allaoua, D., Dejoie, T., Mirallie, S., Jean, M. \& Barriere, P. (2012). Ovarian reserve and in vitro fertilization cycles outcome according to women smoking status and stimulation regimen. Arch. Gynecol. Obstet. 285, 1177-82.

Fuentes, A., Munoz, A., Barnhart, K., Arguello, B., Diaz, M. \& Pommer, R. (2010). Recent cigarette smoking and assisted reproductive technologies outcome. Fertil. Steril. 93, 89-95.

Ganesan, S., Bhattacharya, P. \& Keating, AF. (2013). 7,12Dimethylbenz[a]anthracene exposure induces the DNA repair response in neonatal rat ovaries. Toxicol. Appl. Pharmacol. 272, 690-696.

Gannon, A.M., Stampfli, M.R. \& Foster, W.G. (2012). Cigarette smoke exposure leads to follicle loss via an alternative ovarian cell death pathway in a mouse model. Toxicol. Sci. 125, 274-84.

Gannon, A.M., Stampfli, M.R. \& Foster, W.G. (2013). Cigarette smoke exposure elicits increased autophagy and dysregulation of mitochondrial dynamics in murine granulosa cells. Biol. Reprod. 88, 63.

Gruber, I., Just, A., Birner, M. \& Lösch, A. (2008). Effect of a woman's smoking status on oocyte, zygote, and day 3 preembryo quality in in vitro fertilization and embryo transfer program. Fertil. Steril. 90, 1249-52.

Jennings, P.C., Merriman, J.A., Beckett, E.L., Hansbro, P.M. \& Jones, K.T. (2011). Increased zona pellucida thickness and meiotic spindle disruption in oocytes from cigarette smoking mice. Hum. Reprod. 26, 878-84.

Karuputhula, N.B., Chattopadhyay, R., Chakravarty, B. \& Chaudhury, K. (2013). Oxidative status in granulosa cells of infertile women undergoing IVF. Syst. Biol. Reprod. Med. 59, 91-8.

Kawamura, K., Cheng, Y., Kawamura, N., Takae, S., Okada, A. \& Kawagoe, Y. (2011). Pre-ovulatory LH/hCG surge decreases C-type natriuretic peptide secretion by ovarian granulosa cells to promote meiotic resumption of preovulatory oocytes. Hum. Reprod. 26, 3094-101.

Kumar, M., Pathak, D., Kriplani, A., Ammini, A.C., Talwar, P. \& Dada, R. (2010). Nucleotide variations 
in mitochondrial DNA and supraphysiological ROS levels in cytogenetically normal cases of premature ovarian insufficiency. Arch. Gynecol. Obstet. 282, 695705.

Lim, J. \& Luderer, U. (2011). Oxidative damage increases and antioxidant gene expression decreases with aging in the mouse ovary. Biol. Reprod. 84, 775-82.

Mai, Z., Lei, M., Yu, B., Du, H. \& Liu, J. (2014). The effects of cigarette smoke extract on ovulation., oocyte morphology and ovarian gene expression in mice. PLoS One 9, e9594.

Menezo, Y., Silvestris, E., Dale, B. \& Elder, K. (2016). Oxidative stress and alterations in DNA methylation:two sides of the same coin in reproduction. Reprod. Biomed. Online 33, 668-83.

Nampoothiri, L.P., Agarwal, A. \& Gupta, S. (2007). Effect of co-exposure to lead and cadmium on antioxidant status in rat ovarian granulose cells.. Arch. Toxicol. 81, 145-50.

Neal, M.S., Hughes, E.G., Holloway, A.C. \& Foster, W.G. (2005). Sidestream smoking is equally as damaging as mainstream smoking on IVF outcomes. Hum. Reprod. 20, 2531-5.

Neal, M.S., Zhu, J., Holloway, A.C. \& Foster, W.G. (2007). Follicle growth is inhibited by benzo-[a]-pyrene., at concentrations representative of human exposure., in an isolated rat follicle culture assay. Hum. Reprod. 22, 961-7.

Ngo, C., Chéreau, C., Nicco, C., Weill, B., Chapron, C. \& Batteux, F. (2009). Reactive oxygen species controls endometriosis progression. Am. J. Pathol. 175, 225-34.

Opuwari, C.S. \& Henkel, R.R. (2016). An update on oxidative damage to spermatozoa and oocytes. Biomed. Res. Int. 2016, 9540142, doi:10.1155/2016/9540142.

Paixao, L.L., Gaspar-Reis, R.P., Gonzalez, G.P., Santos, A.S., Santana, A.C., Santos, R.M., Spritzer, P.M. \& NascimentoSaba, C.C. (2012). Cigarette smoke impairs granulosa cell proliferation and oocyte growth after exposure cessation in young Swiss mice: an experimental study. J. Ovarian Res. 5, 25.

Sadeu, J.C. \& Foster, W.G. (2011). Effect of in vitro exposure to benzo-[a]-pyrene., a component of cigarette smoke, on folliculogenesis, steroidogenesis and oocyte nuclear maturation. Reprod. Toxicol. 31, 402-8.

Siddique, S., Sadeau, J.C., Foster, W.G., Feng, Y.L. \& Zhu, J. (2014). In vitro exposure to cigarette smoke induces oxidative stress in follicular cells of $\mathrm{F}_{1}$ hybrid mice. J. Appl. Toxicol. 34, 224-6.

Sobinoff, A.P., Pye, V., Nixon, B., Roman, S.D. \& McLaughlin, E.A. (2012). Jumping the gun: smoking constituent $\mathrm{BaP}$ causes premature primordial follicle activation and impairs oocyte fusibility through oxidative stress. Toxicol. Appl. Pharmacol. 260, 70-80.

Sobinoff, A.P., Beckett, E.L., Jarnicki, A.G., Sutherland, J.M., McCluskey, A., Hansbro, P.M. \& McLaughlin, E.A. (2013). Scrambled and fried: cigarette smoke exposure causes antral follicle destruction and oocyte dysfunction through oxidative stress. Toxicol. Appl. Pharmacol. 271, 156-67.

Tatone, C., Carbone, M.C., Falone, S., Aimola, P., Giardinelli, A., Caserta, D., Marci, R., Pandolfi, A., Ragnelli, A.M. \& Amicarelli, F. (2006). Age-depedent changes in the expression of superoxide dismutases and catalase are associated with ultrastructural modifications in human granulosa cells. Mol. Hum. Reprod. 11, 655-60.

Tiboni, G.M., Bucciarelli, T., Giampietro, F., Sulplizio, M. \& Di Ilio, C. (2004). Influence of cigarette smoking on vitamin $\mathrm{E}$, vitamin $\mathrm{A}, \beta$-carotene and lycopene concentrations in human pre-ovulatory follicular fluid. Int. J. Immunophatol. Pharmacol. 17, 389-93.

Tiboni, G.M., Colangelo, E.C., Leonzio, E. \& Gabriele, E. (2012). Assisted reproduction outcomes after embryo transfers requiring a malleable stylet. J. Assist. Reprod. Genet. 29, 585-8.

Tuttle, A.M., Stämpfli, M. \& Foster, W.G. (2009). Cigarette smoke causes follicle loss in mice ovaries at concentrations representative of human exposure. Hum. Reprod. 24, 1452-9.

Valko, M., Leibfritz, D., Moncola, J., Cronin, M., Mazura, M. \& Telser, J. (2007). Free radicals and antioxidants in normal physiological functions and human disease. Int. J. Biochem. Cell Biol. 39, 44-84.

Waylen, A.L., Metwally, M., Jones, G.L., Wilkinson, A.J. \& Ledger, W.L. (2009). Effects of cigarette smoking upon clinical outcomes of assisted reproduction: a metaanalysis. Hum. Reprod. Update 15, 31-44.

Wright, K.P., Trimarchi, J.R., Allsworth, J. \& Kefee, D. (2006). The effect of female tobacco smoking on IVF outcomes. Hum. Reprod. 21, 2930-4. 